\title{
EL HECHO DEL PRÍNCIPE COMO CAUSAL DE ROMPIMIENTO DEL EQUILIBRIO ECONÓMICO EN LOS CONTRATOS ADMINISTRATIVOS
}

\author{
Eyni Patricia Aponte Duarte \\ Especialización en Contratación Estatal, Universidad Santo Tomás - Bucaramanga (Col); \\ Abogado, Universidad Santo Tomás Bucaramanga (Col). \\ E-mail: maogamarrareyes@hotmail.com \\ Mauricio Gamarra Reyes \\ Especialización en Contratación Estatal, Universidad Santo Tomás - Bucaramanga (Col); \\ Abogado, Universidad Santo Tomás Bucaramanga (Col). \\ E-mail: maogamarrareyes@hotmail.com
}

\section{Resumen}

En el presente artículo se reflexiona sobre la necesidad de estudiar el equilibrio económico en los contratos administrativos y el rompimiento de éste, por tal razón la sociedad, en general, necesita ser orientada con eficacia en el manejo de la contratación estatal, especialmente en el campo financiero del contrato, cada vez que éste se vea afectado en su ecuación contractual por causas ajenas al contratista y atribuibles al Estado al generar costos mayores a los acordados en el contrato, por consiguiente, los sujetos contractuales deben ser orientados sobre las consecuencias de los poderes exorbitantes de la administración frente a la contratación estatal. Por ello, se reflexiona sobre tres aspectos elementales, desarrollados en el marco de la metodología de la investigación: el equilibrio económico en los contratos administrativos, la Teoría del Hecho del Príncipe y sus raíces históricas, el Hecho del Príncipe en el Estado colombiano: su efecto en los contratos públicos.

Palabras clave: Hecho del Príncipe, contratos administrativos, equilibrio económico.

\begin{abstract}
The present article reflexes about the necessity of studying the economic equilibrium within the administrative contract and the breaking of it, for this reason, the society in general needs to be educated with efficiency about the management of state contract, especially in the financial field of the contract, every time its contractual equation is affected by external causes that are attributable to the State who generates more costs on top on the agreed ones within the contract. Considering this, the contractual subjects must be orientated about the consequences of the exorbitant powers of the Administration with respect of the State contracting. It is analyzed in the present text about three fundamental aspects, which are developed within the research's methodology: the economic equilibrium in administrative contracts, the theory of the Prince acts and its historical roots, and the Prince acts in the Colombia state: it effects on the public contracts.
\end{abstract}

Keywords: Prince actions, administrative contracts, economic equilibrium

\section{Résumé}

Cet article s'interroge sur la nécessité d'étudier l'équilibre économique dans les contrats administratifs et la rupture, par conséquent, il la société en général doit être ciblée efficacement dans la gestion des contrats du gouvernement, en particulier dans le domaine contrat financier, chaque fois qu'il est affecté dans son contrat l'équation sans faute de l'entrepreneur et l'État attribuable à générer des coûts plus élevés que convenus dans le contrat, par conséquent, le contrat doit être sujets orientés sur les conséquences des branches l'administration exorbitants contre les contrats gouvernementaux. Par conséquent, nous examinons trois aspects fondamentaux développés dans le cadre de la méthodologie de recherche: l'équilibre économique des contrats administratifs, la théorie Made-Prince et de ses racines historiques, le prince Made in l'Etat colombien: sa effet sur les contrats publics.

Mots-clés : Les actes de l'état, les contrats administratifs, l'équilibre économique. 

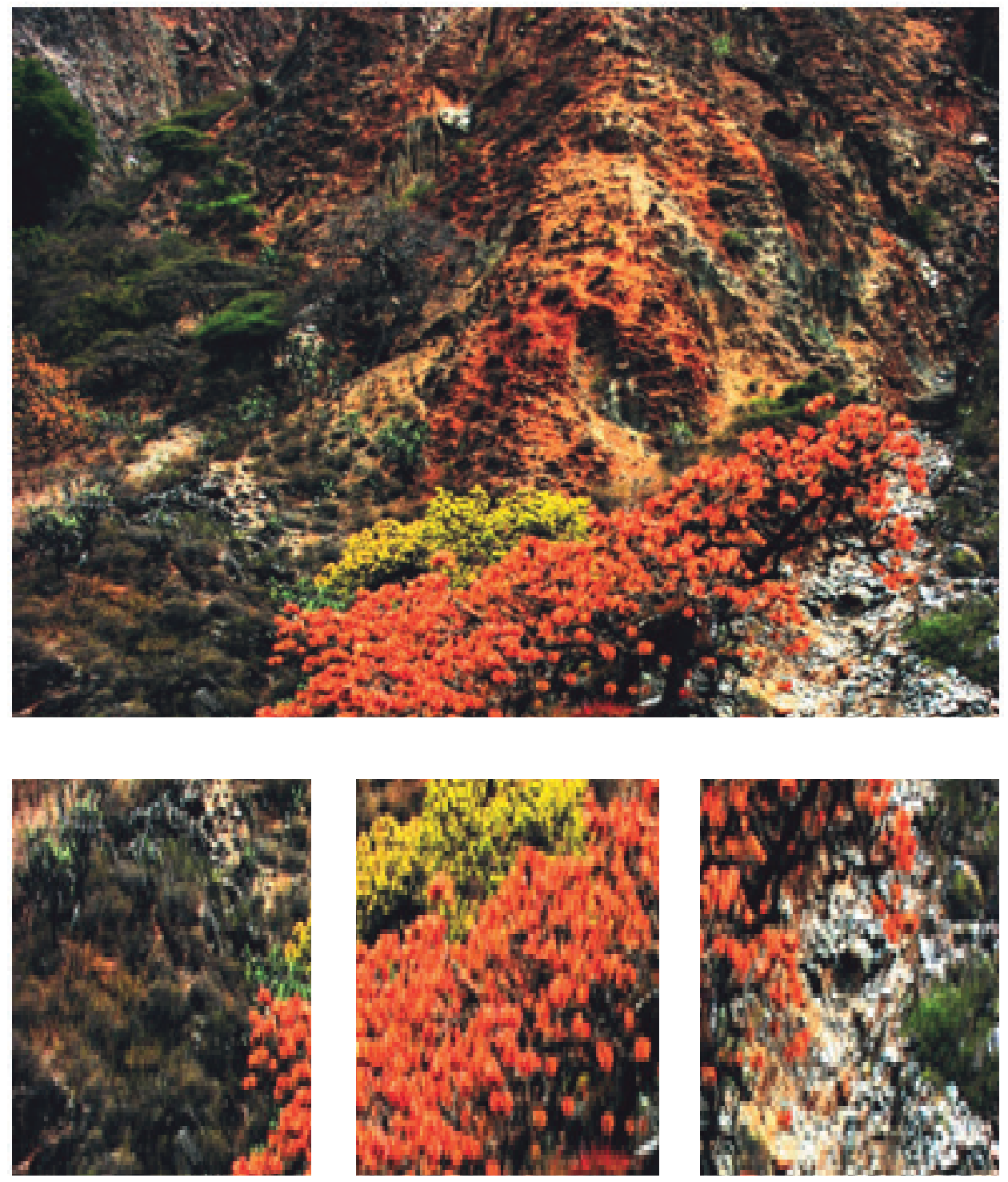

Cañón del Chicamocha - Ceibas Barrigonas

Jorge William Sánchez Latorre 


\section{EL HECHO DEL PRÍNCIPE COMO CAUSAL DE ROMPIMIENTO DEL EQUILIBRIO ECONÓMICO EN LOS CONTRATOS ADMINISTRATIVOS*}

Eyni Patricia Aponte Duarte Mauricio Gamarra Reyes

\section{INTRODUCCIÓN}

La sociedad, en general, necesita ser orientada con eficacia en el manejo de la contratación estatal, especialmente en el campo financiero del contrato, cada vez que éste se vea afectado en su ecuación contractual por causas ajenas al contratista y atribuibles al Estado al generar costos mayores a los acordados en el contrato, por consiguiente, los sujetos contractuales deben ser orientados sobre las consecuencias de los poderes exorbitantes de la administración frente a la contratación estatal. Según lo anterior, es fundamental tener claro el desarrollo y alcance de los principios orientadores de la actividad contractual, así como el criterio auxiliar dictado por los cuerpos colegiados de nuestro país.

Ha sido una constante en el régimen jurídico de los contratos que celebra la administración pública el reconocer el derecho de los contratantes al mantenimiento del equilibrio económico del contrato estatal, plasmado en el principio de la ecuación contractual establecido en el artículo 27 de la Ley 80 de 1993, el cual persigue mantener la igualdad o equivalencia entre derechos y obligaciones entre las partes contratantes, habida cuenta que debe existir una equivalencia reciproca entre las prestaciones. En este orden de ideas, resulta de vital importancia para el ámbito del derecho contractual realizar un acercamiento analítico a la teoría del "hecho del príncipe", toda vez que es una herramienta que permite poner de manifiesto el análisis del equilibrio contractual en los contratos estatales.

Así, el presente trabajo investigativo busca estudiar los motivos por los cuales los contratos estatales se han visto afectados en su equilibrio financiero por el desarrollo

* El artículo reflexiona sobre la teoría del Hecho del Príncipe como causal del rompimiento del equilibro económico en los contratos administrativos. Se deriva del ejercicio de investigación desarrollado por los autores, en el marco de la Asignatura Metodología de la Investigación (Asesor, Docente Javier Díaz Díaz) de la Especialización en Contratación Estatal Cohorte VIII). Posgrados en Derecho Universidad Santo Tomás Bucaramanga (Col). 
de la teoría del 'hecho del príncipe' como causal de rompimiento del principio del equilibrio financiero en los contratos estatales.

Este análisis resulta de gran importancia, no sólo para el profesional del derecho, sino para todos aquellos contratistas que pretendan profundizar sobre el tema de los contratos administrativos que puedan llegar a ser afectados en su equilibrio contractual debido a la imposición de cargas no pactadas en la celebración del contrato y que puedan llegar a afectar financieramente al contratista.

El fundamento jurídico en cuanto al mantenimiento del equilibrio financiero del contrato estatal, radica en el desarrollo del interés público y en los principios constitucionales que orientan la función administrativa, por lo cual, debe examinarse en la generalidad de estos contratos que sean celebrados bajo unos criterios financieros que mantengan una situación coyuntural específica,es posible que tales circunstancias financieras o económicas del contrato estatal resulten alteradas por decisiones o por comportamientos de la administración y no del contratista.

Ante esta realidad de los contratos estatales, la teoría del 'hecho del príncipe' impone a la administración la responsabilidad de asumir cargas derivadas por hechos y actuaciones que hagan más oneroso el desarrollo del contrato en la ejecución de las prestaciones contractuales, de tal manera que la administración tiene el deber de reparar de manera integral del daño que se le pueda llegar a ocasionar al contratista, cuando se verifique que han ocurrido las causales generadoras del 'hecho del príncipe'.

Para profundizar en este frente de análisis, se hace necesario entrar a desentrañar los antecedentes históricos de la Teoría del 'hecho del Principe', al igual que sus fuentes legales y su desarrollo en el marco del sistema legal colombiano.

\section{EL EQUILIBRIO ECONÓMICO EN LOS CONTRATOS ADMINISTRATIVOS}

Manifestadas las pretensiones del trabajo investigativo, resulta fundamental aclarar que el equilibrio económico en los contratos administrativos es un principio establecido desde el orden legal, consistente en la obligación de mantener por parte de los contratantes una "equivalencia honesta" en las prestaciones económicas del contrato estatal. En ese orden de ideas, si tal equilibrio se rompe o resulta alterado, puede nacer el derecho para que el contratista afectado pueda solicitar el restablecimiento de dicho equilibrio al contratante. Sin embargo, se debe dejar claro que no toda alteración en las condiciones contractuales genera la posibilidad de solicitar el restablecimiento del equilibrio financiero del contrato.

Según lo anterior, los contratos estatales, deben ser pactados de tal manera que exista una interdependencia entre las prestaciones, es decir, como contratos sinalagmáticos que son. Debe existir, además, una reciprocidad entre las obligaciones y derechos de cada una de las partes, de tal manera que exista una correspondencia de unas con otras hasta la finalización del contrato. 
La doctrina especializada ha definido el principio del equilibrio financiero del contrato en los siguientes términos:

"El equilibrio financiero, o la ecuación financiera del contrato, es una relación establecida por las partes contratantes en el momento de celebrar el contrato, entre un conjunto de derechos del co contratante y un conjunto de obligaciones de éste, considerado equivalentes: de ahí el nombre de ecuación (equivalenciaigualdad)". (Marienhoff, 1998, p. 469).

En relación con este tema, la jurisprudencia contencioso-administrativa colombiana ha expresado enfáticamente que:

“(...) el contrato estatal debe entonces colmar las expectativas de uno y otro cocontratante, para lo cual se ha previsto la conservación de la ecuación financiera del contrato existente a la fecha en que surge la relación jurídico negocial" (Consejo de Estado, sentencia de 26 de febrero de 2004).

Es decir, se pretende que la correspondencia existente entre las prestaciones correlativas que están a cargo de cada una de las partes del contrato, permanezca durante toda su vigencia.

Según la misma jurisprudencia, lo anterior implica que:

"Cuando las condiciones económicas pactadas a la celebración del contrato, se alteran en perjuicio de una de las partes (contratante-contratista), como consecuencia de hechos que no le son imputables y que ocurren con posterioridad a la celebración del contrato, surge el deber de reparar la ecuación financiera del contrato" (Consejo de Estado, Sentencia de 26 de febrero de 2004).

A su vez la jurisprudencia constitucional colombiana ha dicho que en el derecho administrativo:

"Las prestaciones correlativas de las partes, en virtud del principio de justicia conmutativa, tienen que mantener una equivalencia siguiendo el criterio objetivo de proporción o simetría en el costo económico de las prestaciones, lo que exige que el valor a recibir por el contratista, en razón de los bienes, obras o servicios que le entrega el Estado, deba corresponder al justo precio imperante en el mercado". (Corte Constitucional, Sentencia C-892 de 2001.)

De todo lo dicho resulta claro que en los contratos administrativos las partes contratantes pactan unas determinadas prestaciones que son correspondientes entre sí, las cuales deben mantenerse durante toda la ejecución del contrato y hasta la finalización del mismo. La modificación de estas condiciones, incluso por razones ajenas a los co contratantes, genera una alteración o una ruptura en el equilibrio económico del contrato y nace el deber de restablecimiento de las condiciones previstas al momento de la celebración del contrato estatal. En este sentido, el Consejo de Estado Colombiano ha expresado: 


\begin{abstract}
"Ha sido una constante en el régimen jurídico de los contratos que celebra la administración pública, reconocer el derecho del contratista al mantenimiento del equilibrio económico del contrato, como quiera que la equivalencia de las prestaciones recíprocas, el respeto por las condiciones que las partes tuvieron en cuenta al momento de su celebración y la intangibilidad de la remuneración del contratista, constituyen principios esenciales de esa relación con el Estado". (Consejo de Estado, Sentencia de 29 de mayo de 2003)
\end{abstract}

Según lo anterior se puede concluir, que el principio del equilibrio económico de los contratos administrativos consiste en que las prestaciones que las partes pactan de acuerdo con las condiciones tomadas en consideración al momento de presentar la propuesta o celebrar el contrato, deben permanecer equivalentes hasta la terminación del mismo, de tal manera que si se rompe esa equivalencia, nace para el afectado el derecho a una compensación pecuniaria que restablezca el equilibrio económico del contrato.

\title{
La Teoría del Hecho del Príncipe: raíces históricas
}

Según que en la contratación estatal el contratista ofrece sus servicios al Estado para obtener unos beneficios económicos como contraprestación al cumplimiento de una tarea asignada, 'el hecho del Príncipe' aparece como una medida administrativa, no prevista al momento de la celebración del contrato, que le permite solicitar el restablecimiento del equilibrio económico del convenio en el momento en que sea afectada la ecuación financiera prevista. Esto deviene en que la administración tiene el deber legal de reparar de manera integral el daño que se le pueda llegar a ocasionar al contratista cuando se verifique que han ocurrido las causales generadoras del 'hecho del príncipe'.

Frente a su formulación más antigua, la expresión "fait du prince" o "hecho del príncipe' se circunscribía a una medida arbitraria y violenta, expedida con base en la fuerza coercitiva que ostentaba el titular de la autoridad pública, (Benavides, 2004, pp. 536), al respecto, la jurisprudencia administrativa colombiana apoyó esta posición al manifestar:

Se presenta un 'hecho del príncipe' cuando el Estado expide una medida de carácter general y abstracto que era imprevisible al momento de la celebración del contrato y que incide en forma directa o indirecta en el mismo, alterando en forma extraordinaria o anormal la ecuación financiera surgida al momento de celebrar el contrato, precisando sin embargo, que sólo resulta aplicable la teoría del hecho del príncipe cuando la norma general que tiene incidencia en el contrato es proferida por la entidad contratante. (Consejo de Estado., Sentencia de 18 de Septiembre de 2003).

De igual forma ha señalado la jurisprudencia arbitral que: 
"Por 'hecho del príncipe' en sentido estricto y preciso, ha de entenderse y tal es la postura que adopta este tribunal - toda decisión o conducta proveniente de la misma autoridad que celebró el contrato, cumplida o realizada por ella en ejercicio de atribuciones suyas, propias del poder público, distintas de aquellas de que disfruta o es titular en cuanto contratante, que sobreviniendo durante la ejecución de un contrato administrativo, sea susceptible de causar un perjuicio real, cierto, directo y especial al contratista porque produzca una alteración anormal de la ecuación económico-financiera del contrato y que este no haya podido prever al momento de celebrarlo" (Tribunal de Arbitramento de Cables de Energía y de Telecomunicaciones, laudo de 30 de Septiembre de 1996).

La doctrina, al abordar el estudio del 'hecho del príncipe' o el 'factum principis', sostiene que éste: "alude a medidas administrativas generales que, aunque no modifiquen directamente el objeto del contrato, ni lo pretendan tampoco, inciden o repercuten sobre él haciéndolo más oneroso para el contratista sin culpa de éste" (Marienhoff, 1998, p. 469).

Según dicha apreciación, la teoría del 'hecho del príncipe’ nació para corregir las consecuencias de aquellas intervenciones de los poderes públicos que tuvieran por efecto, afectar con medidas generales, las condiciones jurídicas o de hecho conforme a las cuales el contratista ejecuta su contrato; el 'hecho del príncipe' concierne a las medidas que no tienen por objeto realizar directamente la prerrogativa modificatoria, pero que inciden o repercuten sobre el contrato, haciendo que su cumplimiento sea más oneroso (Cassagne, 2002, p. 140).

Es bien sabido que la norma debe aplicarse con carácter general y no particular, pues de lo contrario se estaría en presencia del ejercicio de los poderes exorbitantes de la administración en el desarrollo del contrato, particularmente el "ius variandi" y no frente al 'hecho del príncipe' (Consejo de Estado, Sent. 4028, de 29 de mayo 2003). A su vez, la doctrina coincide en que para la aplicación de la teoría, la medida de carácter general debe incidir en la economía del contrato y alterar la ecuación económico financiera del mismo, considerada al momento de su celebración, por un álea anormal o extraordinaria, esto es,

"cuando ellas causen una verdadera alteración o trastorno en el contenido del contrato, o cuando la ley o el reglamento afecten alguna circunstancia que pueda considerarse que fue esencial, determinante, en la contratación y que en ese sentido fue decisiva para el co contratante", ya que "el álea "normal", determinante de perjuicios "comunes" u "ordinarios", aún tratándose de resoluciones o disposiciones generales, queda a cargo exclusivo del co contratante, quien debe a bsorber sus consecuencias: tal ocurriría con una resolución de la autoridad pública que únicamente torne algo más oneroso o difícil el cumplimiento de las obligaciones del contrato." (Consejo de Estado, Sent. 4028, de 29 de mayo 2003). 
De acuerdo con lo anterior, para que proceda dicha teoría se establece la exigencia legal de la expedición de un acto general y abstracto que incluye: la incidencia directa o indirecta de ese mismo acto en el contrato estatal, la alteración extraordinaria o anormal de la ecuación financiera del contrato como consecuencia de la vigencia del acto, y la imprevisibilidad del acto general y abstracto al momento de la celebración del contrato estatal.

Según lo anterior, la Sección tercera del Consejo de Estado Colombiano considera que sólo resulta aplicable la teoría del 'hecho del príncipe' cuando la norma general tiene incidencia en el contrato y es proferida por la entidad contratante. (Consejo de Estado, Sent. 4028, de 29 de mayo 2003). Aquí es importante decir que el contrato debe verse afectado en forma grave y anormal como consecuencia de la aplicación de la norma general; esta teoría no resulta procedente frente a alteraciones propias o normales del contrato, por cuanto, todo contratista debe asumir un cierto grado de riesgo.

Según los parámetros para su aplicación debemos decir que la expedición del acto debe darse por la entidad que contrata, en caso contrario, se estaría en presencia de un evento externo a las partes que se encasilla en la teoría de la imprevisión, si se cumplen los demás requisitos para su aplicación.

El fundamento jurídico del derecho al mantenimiento del equilibrio, se encuentra en los fines del interés público que tienen los contratos administrativos y en el carácter de colaborador que tienen los contratistas del Estado de la administración, que obliga a concluir que el patrimonio del contratista no puede ser sacrificado por actos de la propia administración y debe haber una equivalencia honesta entre las prestaciones.

Según lo expuesto por el tratadista Libardo Rodríguez, para poder asegurar que la ruptura del equilibrio financiero del contrato estatal se da por la aplicación de la teoría del 'hecho del príncipe', se deben dar las siguientes condiciones:

- Que el hecho o acontecimiento que produce la alteración de las condiciones contractuales consista en un acto o actuación de la entidad pública contratante en su calidad de autoridad pública.

- Que el acto o actuación que altere las condiciones contractuales sea posterior a la presentación de la propuesta o la celebración del contrato.

- Que el contenido del acto o actuación que altere las condiciones contractuales constituya un álea extraordinario, es decir, que por su carácter excepcional no pudiere haber sido razonablemente previsto por las partes.

- Que el acto o actuación altere en forma extraordinaria y anormal la economía del contrato haciéndolo considerablemente más gravoso. (Rodríguez, 2009 p. 76).

De acuerdo a lo anterior, se tiene que la teoría del 'hecho del príncipe' resulta ser una medida tomada por la administración, específicamente por la entidad contratante, mediante un acto de carácter general, que afecta directamente al contratista, al presentarse con la expedición de ese acto, una alteración económico 
financiera anormal y grave en el contrato celebrado entre éste y la entidad estatal, que da como resultado el nacimiento del derecho en cabeza del contratista a que la entidad restablezca el equilibrio financiero del contrato estatal, que inicialmente fue pactado.

Al hacer un seguimiento a las raíces históricas de la teoría, es importante acudir al Derecho Romano, pues allí se dieron los primeros pasos para su configuración, pues se han encontrado referencias que hablan del equilibrio económico en el contrato de obra, en el que se manejaba la noción de equidad, según que los riesgos en este tipo de contratos no deberían recaer íntegramente en una de las partes contratantes, sino que se debían distribuir de manera uniforme entre ellos. (Ariño, 1968, p.19).

En la Edad Media, bajo la influencia del derecho canónico de acuerdo con los parámetros de San Agustín, se aplicó la idea del "iustum pretium" (justo precio), que permitió aplicar la solución de la lesión a toda clase de contratos. Así, por ejemplo, en el contrato de obra, si el valor de ejecución superaba en más de la mitad el valor pactado, el contratista podía pedir que el contratante pagara el valor completo de la obra. En otras palabras, en el derecho canónico, cuando acaecía un riesgo y se presentaba una disconformidad entre el precio pactado y el justo precio, se imponía el precio justo modificándose el pacto contractual (Ariño, 1968, p. 36). El derecho canónico, en últimas, buscaba restringir el rigor al principio del "pacta sunt servanda", según el cual, los contratos son ley para las partes $\mathrm{y}$, por lo tanto, deben ser cumplidos en los términos en que fueron estipulados.

Ya para la época del derecho privado del siglo XIX, se manejó la concepción individualista y liberal del contrato, vigente en esa época, aplicado para ello el principio de la "Lex contractus", o la "ley del convenio", que se traduce en que el acuerdo es norma jurídica válida entre las partes contratantes, es la misma teoría "Pacta sunt servanda" de los romanos, conocida como el principio del riesgo y ventura. (Escobar, 2003, pp. 409 y ss).

Se concluye que para la época del derecho privado del siglo XIX, se recurrió a los principios del derecho romano, así como al derecho canónico los cuales ya fueron enunciados y explicados con anterioridad frente al referido tema.

\section{EI Hecho del Príncipe en el Estado colombiano: su efecto en los contratos públicos}

De acuerdo a los amplios pronunciamientos que ha sido objeto la figura jurídica del 'hecho del príncipe', siempre se ha mantenido la tesis de que dicha teoría hace parte de un equilibrio económico del contrato; así una de las primeras sentencias que tocó el tema es la proferida por el Dr. Carlos Betancur Jaramillo en 1992, en la que se trató, el tema de impuestos de mejoramiento de materia prima, cobrados a los contratistas como consecuencia de la celebración de un contrato estatal y al respecto manifestó que: 


\begin{abstract}
"Es bien sabido que el equilibrio financiero de un contrato administrativo puede sufrir alteración por un hecho imputable al Estado, como sería, entre otros, el conocido doctrinariamente como hecho del príncipe y determinante del área administrativa. Hecho, siempre de carácter general, que puede emanar o de la misma autoridad contratante o de cualquier órgano del Estado. Si el hecho es de carácter particular y emana de la entidad pública contratante, su manejo deberá enfocarse en función de la responsabilidad contractual y no en razón de la teoría indicada. La medida estatal debe ser de carácter general con incidencia en la ecuación financiera del contrato considerada a la fecha de la celebración del mismo, de tal modo que si la afecta o quebranta en forma anormal o extraordinaria en detrimento del contratista porque hace más onerosa su ejecución, la entidad contratante deberá asumir el riesgo de su restablecimiento." (Consejo de Estado, Sentencia de 27 de marzo de 1992).
\end{abstract}

El anterior razonamiento se presentó gracias a las cláusulas que se celebraban en los contratos estatales en razón a lo establecido en el artículo $9^{\circ}$ de la Ley 50 de 1984 y el cobro del IVA por la importación de materias primas cobrados por la administración a los contratistas en razón a la celebración de dichas cláusulas tendientes a pactar la obligación en cabeza del contratista de cancelar impuestos y derechos que con motivo de la celebración del contrato estatal, cobrase el Gobierno, sin que pudiese exigir compensación alguna por parte de la entidad, sumado a que debía asumir el pago de los gastos de legalización del contrato estatal.

Al respecto de la suscripción de la nombrada cláusula en los contratos estatales, el H. Consejo de Estado en la misma sentencia, se pronunció frente al principio de igualdad, al expresar que con dicha medida se le daba un trato desigual a los contratistas frente a los demás habitantes del Estado, al imponérsele una carga que en últimas alteraba la economía de la ecuación financiera del contrato estatal, al lesionar el patrimonio del contratista y aún más grave sin tener derecho a recibir indemnización alguna y, a su tenor, manifestó:

"El fundamento de tal responsabilidad del Estado hacia su contratante, basada en el "hecho del príncipe", radica en los "principios" de los artículos 16 y 17 de la Constitución Nacional, pues, so pretexto de que cumpla el contrato administrativo (de obvio interés general o público), al contratante, se le estaría dando un trato desigual respecto a los demás habitantes, ya que, aparte de que la norma "general" dictada afecta los derechos individuales de tal contratante, al exigirle el cumplimiento del expresado contrato haríase incidir sobre él una carga que no pesa sobre las demás personas, cuyo derecho, en la especie, no experimenta desmedro específico alguno por razones de interés público. No es concebible que un individuo en especial, a través del cumplimiento de un contrato administrativo sufra el detrimento en su patrimonio obedeciendo esto a razones de interés público. Tampoco es concebible que, en beneficio público, a raíz de la norma "general" dictada que trastorna o altera la economía o ecuación financiera de su contrato, el administrado reciba menoscabo patrimonial sin indemnización, como ocurriría, si en 
las circunstancias expuestas, se pretendiera que el contratante cumpla igualmente sus obligaciones, cargando con una lesiva situación que excede todas las previsiones del contrato: habría ahí un menoscabo de la garantía constitucional de inviolabilidad de la propiedad (artículo 17 de la Ley suprema) - de la que forma parte el derecho nacido de un contrato - , ya que en beneficio del interés general se lesionaría el patrimonio del contratante. A las demás personas o habitantes a quienes afecte la expresada medida "general", no les corresponde, en este supuesto, indemnización alguna, por cuanto la situación de tales personas, al no hallarse éstas vinculadas al Estado por un contrato, no es "diferencial", no pudiendo entonces invocar a su favor la existencia de un perjuicio específico y particular derivado de esa norma "general". En tales casos, la obligación del Estado de indemnizar al contratante es una obvia consecuencia del "principio" también contenido en el expresado artículo 17 de la Constitución, conforme al cual todo menoscabo patrimonial o individual ocasionado por razones de interés público o general, debe ser resarcido: trátese de un principio general de derecho aplicable en todos los supuestos de lesión patrimonial particular por razones de interés público y no sólo en los casos de expropiación por causa de utilidad pública." (Consejo de Estado, Sentencia de 27 de marzo de 1992).

Se aprecia entonces que desde tempranos años el H. Consejo de Estado comenzó a aplicar el principio constitucional de la igualdad, no sólo a nivel individual del ser humano como ser social, sino que además fue más allá y permitió que dicho principio se configurara en las relaciones contractuales del Estado.

Al respecto de los inicios normativos del 'hecho del príncipe' el Consejo de Estado expone que la expedición de la ley 50 de 1984, es un verdadero 'hecho del príncipe', con todas las notas que la doctrina nacional y extranjera le ha dado a la nombrada teoría, y ello por ser una norma de carácter general que afecta el equilibrio económico del contrato, puesto que las entidades estatales no pueden crear impuestos.

Otro fallo del H. Consejo de Estado, de importancia frente a la teoría del 'hecho del príncipe' fue el fechado el 15 de febrero de 1999, en el que fue ponente el Dr. Ricardo Hoyos Duque, pronunciándose sobre la afectación de dicha figura frente al contrato de arrendamiento por la aplicación de los poderes exorbitantes de la administración, modificación o interpretación unilateral del contrato, que causaba lesiones graves al equilibrio económico del contrato frente al contratista, cuando no se reajusta el valor inicialmente pactado al vencimiento del contrato y la administración en su potestad aumenta en una forma exorbitante el canon mensual.

Al respecto dicha Corporación se pronunció de la siguiente forma:

"la revisión del canon y con mayor razón cuando las partes no previeron la forma en que se reajustaría el mismo ante la prórroga automática del contrato, es viable no sólo por aplicación analógica de los artículos 40 . numeral 3o. y 27 de la Ley 80 de 1993, sino porque la ley ha sido cuidadosa en intervenir la fijación del precio en dichos contratos para establecer hasta qué monto las partes pueden convenir el ajuste adecuado que debe pagar el 
arrendatario con el fin de favorecer y equilibrar el resultado económico de los arrendadores."(...)"La entidad pública arrendataria no debió ser indiferente a las circunstancias particulares en que ocupaba el inmueble, porque tenía la obligación de pagar un canon que se ajustara a la realidad económica tanto del arrendador como a las condiciones del bien, en razón a los principios de la buena fe y la equidad a la cual estaba obligada con mayor rigor como ente público. Y es que no solo debe buscarse si hubo esfuerzos del arrendador para prever las dificultades en la ejecución del contrato, sino también cuál fue la actividad de la administración, la diligencia y la lealtad con que actuó frente a su co contratante. Por lo anterior, el juez del contrato en aplicación del principio iura novit curia debe restablecer las condiciones económicas en que debió ejecutarse el contrato y ser mucho más exigente cuando ha sido la administración la que se ha beneficiado de las condiciones en las que se ejecutó en forma efectiva el contrato."

Analizados los anteriores razonamientos, se denota que el H. Consejo de Estado, una vez más, dio prioridad a la aplicación de principios constitucionales, y en esta ocasión, al principio de la buena fe y principio de la equidad, al establecer que las facultades exorbitantes de la administración en la interpretación unilateral del contrato no pueden conllevar a adoptar medidas frente al contratista que se salgan del campo de la realidad, y que es al juez a quien corresponde en últimas velar por que ese equilibrio económico no se vea menoscabado en aplicación del principio "iura novit curia".

Así pues, se detalla una diferencia con la sentencia datada de 1992, explicada inicialmente, en la que sólo se estudió la figura del 'hecho del príncipe' como una figura que nacía por una medida de carácter general, al hablarse de la imposición de los impuestos a los contratistas, pero en la sentencia que se acaba de analizar (19 de febrero de 1999), se vislumbra el acaecer de la administración con su potestad exorbitante, lo que indica que no sólo se presenta la figura del 'hecho del príncipe' por una medida general dictada por el Estado, sino además por la actuación de la administración en su facultad exorbitante.

Ya para el año 2002, el H. Consejo de Estado perfeccionó un poco más el concepto del 'hecho del príncipe' refiriéndose a que esta teoría se debió ajustar en cada caso en concreto, así en sentencia del 07 de marzo de 2002, con ponencia del Dr. Alier Eduardo Hernández Enríquez, la Sala se pronuncio de la siguiente forma:

\footnotetext{
"con la creación de impuestos se puede dar lugar al rompimiento del equilibrio contractual, pero no opera de manera automática, debe establecerse en caso, y que legal, jurisprudencial y doctrinariamente se ha admitido la posibilidad de que el contratista pueda pretender la adopción de medidas tendientes a restablecer el equilibrio económico y financiero del contrato, teniendo en cuenta que existen diversos factores que pueden dar lugar a que "la economía del contrato se lesione, en forma tal, que el contratista no solo pierde la posibilidad de una ganancia justa sino que incurre en pérdidas que deben ser indemnizadas".
} 
(...) “La Sala concluye que la fijación de nuevos impuestos o el incremento de los ya existentes, con carácter general, es una medida que se ajusta a la noción del denominado 'Hecho del Príncipe' y, por lo tanto, puede incidir en el ámbito contractual. Luego, no es acertado aseverar, por lo menos no bajo un juicio absoluto e inmodificable, que los impuestos fijados por la ley no pueden constituir factor que altere la ecuación económica de los contratos, pues ello puede resultar contrario al principio de igualdad ante las cargas públicas. Lo que ocurre es que, el 'Hecho del Príncipe' no opera, a priori, como factor desencadenante de la ruptura del equilibrio económico de los contratos; de allí que serán las particularidades de cada caso las que permitirán llegar a tal conclusión, siendo indispensable incorporar en el análisis de la hipótesis concreta, el criterio de previsibilidad." (Consejo de Estado, Sentencia del 7 de marzo de 2002).

Finalmente, para el año 2005, el Consejo de Estado se pronunció frente a la figura del 'hecho del príncipe' en sentencia del Cinco (5) de mayo de dos mil cinco (2005), con ponencia del Dr. Alier Eduardo Hernández Enríquez, al advirtir que cuando se presenta el fenómeno del 'hecho del príncipe' en los contratos, el acto que se demanda debe ser de contenido general y abstracto y que no se hace necesario demandar su nulidad, sino simplemente solicitar que se está frente al 'hecho del príncipe', es decir, invocar dicha teoría en la demanda, sin que sea necesario probar que el acto, por medio del cual la administración rompió el equilibrio económico del contrato es ilegal.

Esta situación antes expuesta permite afirmar que la nulidad del acto de modificación unilateral del contrato, no es constitutiva del desequilibrio financiero del contrato por el 'Hecho del Príncipe', sino de responsabilidad contractual por el ejercicio irregular de los poderes exorbitantes; aún cuando uno y otro conduzcan a la reparación integral de los daños que pruebe el contratista. La diferencia radica en que, en el primer supuesto, es indispensable desvirtuar la presunción de legalidad de los actos contractuales, en tanto que, en el segundo resulta necesario probar la existencia de un acto general y abstracto imprevisible para las partes, que incidió indirectamente en el contrato, y alteró gravemente su ecuación económica; sin que sea necesario probar que era un acto ilegal. El actor también dejó de lado la existencia del ius variandi, como un evento típico de desequilibrio financiero del contrato, que ha de invocarse cuando un acto particular y concreto proferido por la administración contratante, modifica o interpreta el contrato en forma legítima, pero produce la alteración de la ecuación financiera del contrato, en perjuicio del contratista.

Así las cosas, es claro que la demanda del acto que rompe el equilibrio económico del contrato define responsabilidad patrimonial, pero no es necesario demostrar su ilegalidad para que se constituya la figura del 'hecho del príncipe.

Los pronunciamientos que se han dado con posterioridad han sido pocos, y su análisis se ha reducido a establecer que el 'hecho del príncipe' es un figura que 
siempre va a atentar contra el equilibrio económico del contrato, en general se da por la imposición de pago de impuestos o elevación en los valores de los materiales que no estaban previstos al momento de la celebración del contrato de obra.

Del anterior análisis se puede concluir que el Consejo de Estado ha mantenido dos criterios frente a la teoría del 'hecho del príncipe', uno que para que se configure se necesita que la medida sea de carácter general como, por ejemplo, la imposición del pago de impuestos, y el otro que es necesario que la administración en su ámbito de ejercer la potestad exorbitante genere un rompimiento del equilibrio contractual tan evidente que se asuma que el cambio o la exigencia se ha salido de la realidad, no solo contractual, sino legal y social, igual en el evento en que se presente cualquiera de las situaciones de hecho previstas, se debe analizar el caso en concreto y demostrar por parte del contratista que el equilibrio económico del contrato se ha roto.

Ahora bien, el Consejo de Estado, recientemente ha tratado el tema en sentencia del cuatro (4) de febrero de 2010, con ponencia del Dr. Enrique Gil Botero y frente a la teoría del 'hecho de príncipe', consideró la Sala que la generalidad resulta cuando el desequilibrio se presente por la voluntad de la entidad contratante y la excepción por la expedición de un acto legislativo, siempre que dicho acto sea de carácter general y se pruebe la afectación de la economía del contrato por cuenta del contratista, así:

“(...) sólo resulta aplicable la teoría del 'hecho del príncipe' cuando la norma general que tiene incidencia en el contrato es proferida por la entidad contratante. Si la misma proviene de otra autoridad, se estaría frente a un evento externo a las partes que encuadraría mejor en la teoría de la imprevisión. Con respecto a los otros supuestos de la teoría, la norma debe ser de carácter general y no particular, pues de lo contrario se estaría en presencia del ejercicio de los poderes exorbitantes con los que cuenta la administración en el desarrollo del contrato (particularmente el ius variandi) y no frente al 'hecho del príncipe'. El contrato debe afectarse en forma grave y anormal como consecuencia de la aplicación de la norma general; esta teoría no resulta procedente frente a alteraciones propias o normales del contrato, por cuanto todo contratista debe asumir un cierto grado de riesgo (...) De ahí que la dificultad que enfrenta el juez, al momento de definir la aplicación de la teoría del 'hecho del príncipe', consiste en la calificación de la medida, toda vez que si la manifestación por excelencia del soberano es la ley, no existe, en principio, como consecuencia de ésta, responsabilidad del Estado. Ese principio, sin embargo, admite excepciones y se acepta la responsabilidad por acto legislativo cuando el perjuicio sea especial con fundamento en la ruptura del principio de igualdad frente a las cargas públicas. La expedición de la norma debe ser razonablemente imprevista para las partes del contrato; debe tratarse de un hecho nuevo para los co contratantes, que por esta circunstancia no fue tenido en cuenta al momento de su celebración. En cuanto a los efectos derivados de la configuración del 'hecho del príncipe', demostrado el rompimiento del equilibrio financiero del contrato estatal, como consecuencia de un acto imputable a la entidad contratante, surge para ésta la obligación de indemnizar todos los perjuicios derivados del mismo." (Consejo de Estado, Sentencia del 4 de febrero de 2010). 
Del anterior marco jurisprudencial se puede extraer que en definitiva la teoría del 'hecho del príncipe' se aplica en los contratos estatales y nace de la propia voluntad de la administración, es decir, de la entidad contratante y, así mismo, genera el rompimiento del equilibrio financiero del contrato para el contratista, por consiguiente, es la administración quien debe responder por ese quebranto en las finanzas del negocio jurídico estatal y para que se configure debe existir una disposición de la dependencia del Estado que afecte directamente el equilibrio económico del contrato y haga más difícil la situación del contratista. La teoría del 'hecho del príncipe' se asocia con determinaciones del Estado que afecten la economía del contrato por vía refleja, es decir, se refiere a decisiones adoptadas por alguna esfera oficial que no tienen por objeto el contrato mismo, sino que se refieren de manera general, abstracta, dirigida a toda la población o parte de ella, pero que producen un mayor gasto o afecta las utilidades de un determinado contrato en la medida en que implica una nueva erogación o una disminución de la utilidad que se previó en la elaboración de la oferta. (Procuraduría Quinta Judicial ante el Tribunal Administrativo de Cundinamarca, Concepto No. 013 - 06- del 28 de febrero de 2006).

En general la consecuencia derivada de la aplicación de la teoría del Hecho del Príncipe, es principalmente el desequilibrio económico del contrato, generándose un desequilibrio en las cargas de tipo económico que deben sobrellevar las partes; se debe tener en cuenta para ello que la administración siempre tendrá un lugar preponderante sobre el contratista, así como el mismo Estado, por ello, cuando el contratista se sienta afectado por dicho fenómeno, deberá recurrir al juez administrativo para que le reconozca que el equilibrio económico del contrato se ha roto y proceda a decretar la existencia del 'hecho del príncipe'.

Entonces el acto lesivo emanado de cualquier órgano del Estado, sea o no de la entidad pública que celebró el contrato, habilita al contratista para requerir una reparación integral por parte del juez administrativo, invoca para ello en su demanda la teoría del 'hecho del príncipe' y debe demostrar que dicho acontecimiento afectó el normal desarrollo del contrato proveniente de actos o hechos de los órganos estatales y justificar así una reparación integral. La acción a interponer corresponde a la acción contractual.

\section{CONCLUSIONES}

- La teoría del Hecho del Príncipe es una medida administrativa de carácter general expedida por la entidad contratante y afecta el equilibrio económico del contrato, así como el principio de la ecuación contractual establecido en el artículo 27 de la Ley 80 de 1993, que perjudica al contratista.

- Debido a la teoría del 'hecho del príncipe', el contratista debe asumir gastos por fuera de lo normalmente señalados en el contrato como, por ejemplo, pagar un valor más elevado por materiales de obra, en el caso de los 
contratos de obra.

- Por otra parte se concluye que la teoría del 'hecho del príncipe' es una teoría poco manejada por la doctrina colombiana pero sí, por el contrario, manejada por la jurisprudencia colombiana.- En recientes fallos, el $\mathrm{H}$. Consejo de Estado se ha pronunciado al respecto y ha señalado que sólo se causa el perjuicio al contratista si la medida del hecho del príncipe proviene de la entidad contratante.

- En fin ya sea que provenga la medida del ente estatal, o de la entidad contratante, lo cierto es que el 'hecho del príncipe' generara siempre un perjuicio para el contratista, rompiéndose el equilibrio económico del contrato, para lo cual debe el contratista acudir ante el juez de lo contencioso administrativo en acción contractual y solicitar el reparo de su perjuicio, así como el restablecimiento de la ecuación contractual.

\section{REFERENCIAS}

Benavides J L. (1999). El contrato Estatal.

Corte Constitucional. Sentencia C-892 de 2001 (Magistrado Ponente Rodrigo Escobar Gil; agosto 22 de 2001.)

Consejo de Estado. Sala de lo Contencioso Administrativo. Sección Tercera. Expediente No. 6353. (Consejero Ponente. Carlos Betancur Jaramillo; marzo 27 de 1.992).

Consejo de Estado. Sala de lo Contencioso Administrativo. Sección Tercera. Expediente No. 15.665. (Consejero Ponente. Enrique Gil Botero; febrero 4 de 2.010).

Consejo de Estado. Sala de lo Contencioso Administrativo. Sección Tercera. Expediente No. 21588. (Consejero Ponente. Alier Eduardo Hernández Enríquez; marzo 7 de 2.002).

Consejo de Estado. Sala de lo Contencioso Administrativo. Sección Tercera. Expediente No. 11184. (Consejero Ponente. Ricardo Hoyos Duque; febrero 15 de 1.999).

Consejo de Estado. Sala de lo Contencioso Administrativo. Sección Tercera. Expediente No. 2858. (Consejero Ponente. Carlos Betancur Jaramillo; marzo 27 de 1.992).

Consejo de Estado. Sala de lo Contencioso Administrativo. Sección Tercera. Sentencia 4028. (Consejero Ponente. Ricardo Hoyos Duque; mayo 29 de 2.003).

Consejo de Estado. Sala de lo Contencioso Administrativo. Sección Tercera. Expediente No. 15119. (Consejero Ponente. Ramiro Saavedra Becerra; septiembre 18 de 2.003).

Consejo de Estado. Sala de lo Contencioso Administrativo. Sección Tercera. 
Expediente No. 14043. (Consejero Ponente. Germán Rodríguez Villamizar; febrero 26 de 2.004).

Consejo de Estado. Sala de Consulta y Servicio Civil. Expediente No. 1551. (Consejero Ponente. Gustavo Aponte Santos; febrero 26 de 2.004).

Constitución Política de Colombia. (2009) Editorial Legis

Cassagne J C, El equilibrio económico del contrato estatal. Ed. Buenos Aires.

Escobar Gil R, Teoría General de los Contratos de la Administración Pública. Ed. Legis. Bogotá D. C. 2003

Gaspar Ariño Ortiz, Teoría del Equivalente Económico en los Contratos Administrativos.

Marrienhoff, S, M, Tratado de Derecho Administrativo. Editorial Buenos Aires

Procuraduría Quinta Judicial ante el Tribunal Administrativo de Cundinamarca. Concepto No.013 - 06. 28 de febrero de 2.006. Bogotá D. C.

Rodríguez Rodríguez L, El equilibrio económico en los contratos administrativos. Editorial Temis. Bogotá D. C. 2009.

Tribunal de Arbitramento de Cables de Energía y de Telecomunicaciones "Centelsa S.A.” contra Empresa de Energía de Bogotá, Laudo de 30 de Septiembre de 1996, en Laudos Arbítrales- versión CD, Bogotá D. C., Cámara de Comercio de Bogotá, marzo de 2008. 



\section{NORMAS DE PUBLICACIÓN}

La revista IUSTITIA de la Facultad de Derecho Universidad Santo Tomás (Seccional Bucaramanga), atendiendo al Departamento Administrativo de Ciencia, Tecnología e Innovación, Colciencias y el Sistema Nacional de Indexación y Homologación de Revistas Especializadas de CT+ -Servicio de Indexación, expone las normas de publicación necesarias para la presentación de contribuciones:

Para la aceptación de los artículos por parte del Comité Editorial, se exigirá, que los artículos sean inéditos y originales (sin publicación parcial o total).

El artículo debe estar acompañado del Curriculum Vitae completo del autor: nombre completo del autor, fecha completa de nacimiento, nacionalidad, nivel de escolaridad, nombre de la institución, centro de investigación, o institución a la cual pertenece, cargo que desempeña. Las publicaciones de artículos y reseñas de capítulos de libros y libros deben presentarse (en el curriculum) con toda la información correspondiente: Título, nombre de la revista o compilación, ISSN o ISBN, número de páginas total del texto completo, número de páginas del artículo o capítulo, año de publicación, editorial y país.

El texto debe presentarse en medio magnético, en formato Word, Normas APA, cuartillas 25 - 30, espacio medio, en letra Times New Roman 12, debe tener un resumen no superior a 10 renglones, abstract, palabras clave, key words. En relación con los anexos deben adjuntarse la lista de gráficas y cuadros, con su correspondiente numeración y página. Las tablas y figuras deben presentarse en formato original para poder hacer los ajustes necesarios de edición.

Los artículos recibidos serán remitidos a pares evaluadores, a quienes se les solicitará tener en cuenta en la evaluación, la calidad y el rigor académico del texto, como también la exigencia de las normas correspondientes a los trabajos académicos de publicación.

Recepción de artículos: Revista IUSTITIA: RevistaIUSTITIA@ustabuca.edu.co; coordinvder-ustabuca@hotmail.com

CP- Dirección para correspondencia (Sede Bucaramanga): Cra 18 No. 9 - 27. Bucaramanga - Santander - Colombia. PBX: 6800801 Ext. 2506.

La convocatoria (2012) para recibir artículos será entre Marzo 1 - Agosto 31. El idioma de publicación es el español, se aceptan artículos en inglés, francés, italiano y portugués. El Comité Editorial enviará comunicación sobre la aprobación o no de artículo, en un término no mayor a cuatro (4) meses.

Actualmente se tramitan procesos de registro ante la comunidad especializada.

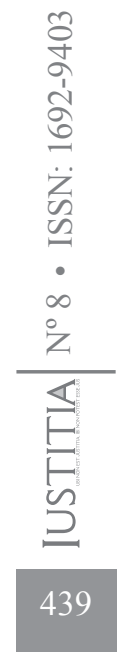


Esta obra se terminó de imprimir en el mes de diciembre de 2011 en la Universidad Santo Tomás Seccional Bucaramanga 